\title{
Seleção de isolados de Colletotrichum da biodiversidade da Amazônia como produtores de lacases utilizando uma metodologia simplificada
}

\section{Screening of Colletotrichum isolates from the Amazon biodiversity as producers of laccases using a simple methodology}

\author{
Gilmara Carvalho Martinez ${ }^{1}$; Ellen Cristine Giese ${ }^{2}$; José Odair Pereira \\ Robert F. H. Dekker'; Aneli de Melo Barbosa ${ }^{5 *}$
}

\section{Resumo}

O presente trabalho apresenta uma metodologia simples e rápida para selecionar isolados fúngicos produtores de lacases. Foram avaliados quinze isolados de Colletotrichum da biodiversidade da Amazônia (obtidos de cumarú, puerária, cupuaçu e plantas daninhas), além de um isolado de espinheira santa do sul do país, quanto à produção de lacases. A atividade da enzima foi determinada utilizandose os substratos ABTS e o DMP. Somente os isolados de puerária $\mathrm{P}_{2}$ e $\mathrm{P}_{3}$ não apresentaram atividade sobre o substrato DMP. Os isolados $\mathrm{D}_{3}$ (planta daninha), $\mathrm{M}_{3}$ (espinheira santa), $\mathrm{C}_{2}$ e $\mathrm{C}_{3}$ (cumarú) foram selecionados e comparados quanto à produção de lacases em cultivos líquidos estáticos e agitados, utilizando-se o Pleurotus ostreatus, um basidiomiceto produtor de lacase, como referência. A maior atividade de lacase foi detectada apenas nos cultivos estáticos do isolado $\mathrm{D}_{3}(35 \mathrm{U} / 1 \mathrm{em} \mathrm{ABTS} ; 8 \mathrm{U} / 1 \mathrm{em}$ e DMP).

Palavras-chave: Colletotrichum, lacases, biodiversidade amazônica

\begin{abstract}
This work presents a simple and rapid technique to select fungal strains with the ability to produce laccases. Fifteen strains of Colletotrichum spp. from the Amazon region (isolated from cumarú, puerária, cupuaçu and weed plants), as well as a strain isolated from "espinheira santa" in the south of Brazil, were found to produce laccases. Laccase activity was assayed using ABTS and DMP as putative substrates. Only Colletotrichum isolates of puero $\left(\mathrm{P}_{2}\right.$ and $\left.\mathrm{P}_{3}\right)$ did not present activity towards DMP. Isolates $\mathrm{D}_{3}$ (weed plants), $\mathrm{M}_{3}$ (espinheira santa), $\mathrm{C}_{2}$ and $\mathrm{C}_{3}$ (cumarú) were selected, and were compared with the basidiomycete Pleurotus ostreatus used as a reference laccase producer under stationary and submerged culture conditions. Highest laccase activity was detected only in the stationary cultures of Colletotrichum isolate $\mathrm{D}_{3}$ assayed against ABTS (35 U/1) and DMP (8 U/1).
\end{abstract}

Key words: Colletotrichum, laccases, amazon biodiversity

1 Especialista em Bioquímica Aplicada, Depto de Bioquímica e Biotecnologia, CCE, UEL, Londrina, PR.

Mestre em Biotecnologia, Depto de Bioquímica e Biotecnologia, CCE, UEL, Londrina, PR.

Docente da Faculdade de Ciências Agrárias, UFAM, Manaus, AM.

4 CNPq-Professor Visitante do Departamento de Bioquímica e Biotecnologia, CCE, UEL, Londrina, PR.

5 Docente do Departamento de Bioquímica e Biotecnologia, CCE, UEL, Londrina, PR. Email: aneli@uel.br

* Autor para correspondência 


\section{Introdução}

As espécies fúngicas pertencentes ao gênero Colletotrichum são conhecidas como fungos endofíticos, os quais habitam o interior dos tecidos aparentemente saudáveis das plantas em algum estágio da vida, formando infecções pouco visíveis (PETRINI; PEREIRA; AZEVEDO, 1993). Os microrganismos endofíticos podem atuar como simbiontes, protegendo as plantas hospedeiras contra pragas e patógenos (AZEVEDO et al., 2000), ou como parasitas após serem estimulados ecológica e fisiologicamente, podendo se manifestar como patógenos e causar danos irreversíveis às plantas hospedeiras (OKANE; NAKAGIRI; ITO, 1998).

Assim, as espécies de Colletotrichum também são conhecidas como fitopatógenas e atacam principalmente árvores frutíferas com grande valor comercial, como mangueiras, bananeiras e guaranazeiros, entre outras (ARDI et al., 1998). Estes fungos interagem de maneira diferenciada de acordo com cada hospedeiro, podendo atacar diferentes partes da planta, como caules, folhas, flores e frutos (KIM; OH; YANG, 1999). O C. acucatum, por exemplo, tem sido descrito como patógeno de árvores cítricas, contaminando especialmente flores de limoeiros (CHUNG; SHILTS; TIMMER, 2002), enquanto que espécies de C. coffeanum têm sido severamente combatidas por prejudicarem as lavouras de café, destruindo os frutos (KING'ORI; MASABA, 1991).

As doenças mais comuns causadas pelos fungos do gênero Colletotrichum são a antracnose e a ramulose. A antracnose é causada principalmente pelo C. guaranicola, sendo que o processo de infecção por este fungo inicia-se na cutícula e parede celular das folhas, e atinge a epiderme e o parênquima, levando à necrose rapidamente (BENTES; BARRETO, 2004). No Brasil, as culturas de guaranazeiro (Paullinia cupana var. sorbilis) são as mais prejudicadas por este tipo de infecção. Já a ramulose causa prejuízos às plantações de algodoeiro (Gossypium hirsutum), os quais são infectados pelo $C$. gossypii, um patógeno associado às sementes de algodão (SILVA-MANN et al., 2002). Assim, diferentes métodos de controle biológico, químico e genético têm sido estudados no combate à disseminação destas espécies fúngicas em diferentes tipos de lavouras (KUMAR; SATYAVIR, 1998; MENDONÇA; SANTOS; RAMALHO, 1998).

Estudos sobre a interação entre os fungos do gênero Colletotrichum e as plantas hospedeiras têm sido realizados (GOODWIN; OLIVER; HSIANG, 2004). As espécies que vêm sendo mais estudadas são o C. guaranicola e o C. gloeosporioides, patógeno de árvores frutíferas sensíveis, como o maracujazeiro (ROCHA; OLIVEIRA; MENEZES, 1998). A fitopatogenicidade parece estar vinculada à capacidade do microrganismo de produzir enzimas extracelulares capazes de degradar os compostos presentes nas plantas, em especial a lignina. As principais enzimas envolvidas na degradação da lignina são as lignina-peroxidases, as manganêsperoxidases e as lacases (LEONOWICZ et al., 2001).

A produção de enzimas pelos fungos deste gênero tem sido pouco descrita na literatura. Dentre as enzimas mais estudadas podem ser citadas as pectinases e poligalacturonases, responsáveis pelo ataque à pectina presente em folhas e frutos das plantas hospedeiras (HERBERT et al., 2004) e as quitinases, as quais atuam na degradação da quitina presente na parede celular de fungos e também em insetos (SOUZA et al., 2003). Anderson e Nicholson (1996) demonstraram pela primeira vez, a atividade de lacase na mucilagem extracelular de C. graminicola. Recentemente, Levin et al. (2007) selecionaram o C. truncatum como o melhor produtor de lacases entre 10 cepas de Colletotrichum estudadas.

A lacase (benzenodiol: oxigênio oxidoredutase, EC 1.10.3.2) é uma enzima que oxida uma variedade de compostos aromáticos, catalisando a remoção de elétrons e prótons de grupos hidróxifenólicos 
e aminoaromáticos (MAYER; STAPLES, 2002). Estas polifenol oxidases possuem diversas aplicações biotecnológicas, destacando-se o seu uso na confecção de biossensores para detecção de compostos fenólicos (ROY et al., 2005), na degradação de compostos aromáticos (JAOUANI et al., 2005), como mediador da oxidação de resíduos da indústria de polpa Kraft (ELEGIR et al., 2005), entre outros (COUTO; HERRERA, 2006).

As lacases estão envolvidas em diferentes processos biológicos como na esporulação, na produção de pigmentos durante o desenvolvimento do corpo de frutificação e na patogênese, entre outros (COLL et al., 1993). A seleção de isolados fúngicos produtores de lacases é realizada em várias etapas através de fermentações submersas que despedem tempo e o uso excessivo de reagentes (LEVIN et al., 2007). Assim, o objetivo deste trabalho foi desenvolver uma metodologia simples e confiável para avaliar a produção de lacases de 15 isolados de Colletotrichum, sendo 14 isolados de plantas da floresta Amazônica, a qual possui a biodiversidade mais rica do mundo, e um de espinheira santa do sul do Brasil, uma vez que o estudo da produção de lacases por estes isolados poderá contribuir futuramente nas pesquisas sobre a interação entre estes fungos e as plantas hospedeiras.

\section{Materiais e Métodos}

\section{Microrganismos}

Os quinze isolados de Colletotrichum procedentes do interior de folhas sadias de diversos hospedeiros da floresta Amazônica foram gentilmente cedidos pelo Prof. Dr. José Odair Pereira (Faculdade de Ciências Agrárias, Universidade Federal de Manaus). O microrganismo utilizado como referência Pleurotus ostreatus (linhagem Flórida) foi cedida pelo Prof. Dr. Raúl Jorge Hernan Castro-Gómez da coleção de cepas do Departamento de Tecnologia de Alimentos e Medicamentos da Universidade Estadual de Londrina. Os fungos estudados foram mantidos em meio sólido inclinado de batata-agar-dextrose (BDA) a $4{ }^{\circ} \mathrm{C}$, com repiques trimestrais.

Avaliação e seleção dos isolados produtores de lacases em meio sólido de cultivo

Para selecionar os isolados de Colletotrichum produtores de lacases, as quinze cepas isoladas e o microrganismo de referência foram crescidos em meio sólido de agar $(20 \mathrm{~g} / \mathrm{l})$, glucose $(10 \mathrm{~g} / \mathrm{l})$ e extrato de levedura ( $2 \mathrm{~g} / \mathrm{l})$, codificado como meio EGA. As placas foram mantidas em sala termostatizada a 28 ${ }^{\circ} \mathrm{C}$ sob iluminação constante durante 11 dias. Após este período, cinco discos de $0,7 \mathrm{~cm}$ de diâmetro contendo micélios fúngicos foram transferidos para tubos de ensaio contendo $3 \mathrm{ml}$ de tampão citratofosfato $(40 \mathrm{mM}) \mathrm{pH} 4,0$ (teste para o substrato ABTS) ou tampão citrato-fosfato $(57 \mathrm{mM}) \mathrm{pH}$ 5,0 (teste para o substrato DMP). Os tubos foram vedados e mantidos em câmara de refrigeração a $4{ }^{\circ} \mathrm{C}$ durante uma hora, para eluição da enzima. A seguir, foram filtrados em lã de vidro e submetidos aos ensaios de atividade enzimática.

\section{Meio líquido de cultivo e condições de crescimento}

Os cultivos em meio líquido foram desenvolvidos em frascos de Erlenmeyer de $125 \mathrm{ml}$ contendo $25 \mathrm{ml}$ de meio mínimo de sais de Vogel (1956), glucose $(20 \mathrm{~g} / 1)$ e extrato de levedura $(2 \mathrm{~g} / \mathrm{l})$. Cada frasco foi inoculado com três discos contendo micélios fúngicos e foram mantidos estáticos ou sob agitação constate a $180 \mathrm{rpm}$, durante 11 dias a $28^{\circ} \mathrm{C}$. Os cultivos foram realizados em triplicata e os resultados obtidos foram descritos como média e desvio-padrão.

\section{Determinações enzimáticas}

Os cultivos foram interrompidos através de centrifugação por 15 minutos a $4500 \mathrm{rpm}$. Os sobrenadantes foram coletados sob banho de gelo, 
sendo então utilizados para as determinações analíticas e enzimáticas. A atividade da lacase foi determinada de acordo com Barbosa, Dekker e Hardy (1996), utilizando-se como substratos o ácido 2,2'-azino-bis-(3-etilbenzotiazolina-6sulfônico) (ABTS) e o 2,6-dimetoxifenol (DMP). Para o substrato ABTS, os ensaios foram incubados a $38^{\circ} \mathrm{C}$, em tampão McIlvaine (40 mM) pH 4,0 e as leituras foram realizadas a $420 \mathrm{~nm}$. Para o substrato DMP, os ensaios foram incubados em tampão McIlvaine (57 mM) pH 5,0 e as leituras realizadas a $468 \mathrm{~nm}$. A unidade de atividade da lacase foi definida como o número em micromoles de substrato oxidados por minuto por litro de extrato enzimático.

\section{Métodos analíticos}

A biomassa fúngica foi determinada por gravimetria após secagem em estufa a $70^{\circ} \mathrm{C}$ até peso constante. Os açúcares redutores foram determinados através do método descrito por Somogyi (1945) e Nelson (1944). As proteínas foram determinadas pelo método de Lowry modificado por Hartree (1972).

\section{Resultados e Discussão}

Tabela 1. Origem das espécies de Colletotrichum isoladas de diferentes plantas hospedeiras.

\begin{tabular}{ll}
\hline Planta Hospedeira & Código do Isolado \\
\hline Espinheira santa (Maytenus aquifolia) M.2.1.3 & $\mathrm{M}_{1}$ \\
Espinheira santa (Maytenus aquifolia) M.1.4.2 & $\mathrm{M}_{2}$ \\
Espinheira santa (Maytenus aquifolia) M.1.2.4 & $\mathrm{M}_{3}$ \\
Espinheira santa (Maytenus aquifolia) M.2.3.2 & $\mathrm{M}_{4}$ \\
Planta daninha (Scleria pterota) D.2.2.1 & $\mathrm{D}_{1}$ \\
Planta daninha (Scleria pterota) D.8.3.1 & $\mathrm{D}_{2}$ \\
Planta daninha (Scleria pterota) D.7.4.4 & $\mathrm{D}_{3}$ \\
Cupuaçu (Theobroma grandflorum) lg.1.9.3.5 & $\mathrm{T}_{1}$ \\
Cupuaçu (Theobroma grandflorum) lg. 1.1.4.1 & $\mathrm{T}_{2}$ \\
Puerária (Pueraria phaseoloides) P.7.2.1 & $\mathrm{P}_{1}$ \\
Puerária (Pueraria phaseoloides) P.4.1.1 & $\mathrm{P}_{2}$ \\
Puerária (Pueraria phaseoloides) P.3.2.4 & $\mathrm{P}_{3}$ \\
Cumarú (Dpterix odorata) C.6.A.4.1 & $\mathrm{C}_{1}$ \\
Cumarú (Dpterix odorata) C.7.B.4.5 & $\mathrm{C}_{2}$ \\
Cumarú (Dpterix odorata) C.4.A.4.3 & $\mathrm{C}_{3}$ \\
\hline
\end{tabular}

Dentre as espécies fúngicas, os basidiomicetos têm sido mais estudados quanto a produção de enzimas ligninolíticas. O Pleurotus ostreatus é um basidiomiceto produtor de lacases, as quais têm sido utilizadas na confecção de biossensores para detectar catecolaminas (SUGUIMOTO et al., 2001; LEITE; FATIBELLO-FILHO, BARBOSA, 2003;). Neste trabalho, um isolado de $P$. ostreatus (linhagem Flórida) foi utilizado como fungo de referência para avaliar a eficiência do método utilizado para a detecção de lacases nos meios de cultivos das linhagens selvagens do deuteromiceto Colletotrichum.

Os fungos deuteromicetos, assim como os ascomicetos, também são descritos na literatura como produtores destas polifenol oxidases (IKEHATA; BUCHANAN; SMITH, 2004). Os isolados de Colletotrichum utilizados no presente trabalho foram codificados e estão relacionados na Tabela 1. A seleção dos microrganismos produtores de lacase foi realizada através do crescimento dos mesmos em meio sólido de BDA durante 11 dias, sob iluminação constante, de acordo com Anderson e Nicholson (1996). Este período de desenvolvimento foi suficiente para que todas as espécies fúngicas avaliadas colonizassem por completo as superfícies dos meios nas placas de Petri. 
$\mathrm{Na}$ etapa de pré-seleção dos isolados fúngicos produtores de lacase, a enzima foi eluída com os respectivos tampões citrato-fosfato $\mathrm{pH}(4,0$ e 5,0), os quais foram pré-selecionados de acordo com as condições padronizadas para a determinação da atividade de lacase com os substratos ABTS e DMP, descritas anteriormente para o fungo de referência Pleurotus ostreatus (LEITE et al., 1998; REZENDE et al., 2005). Os testes preliminares demonstraram que o período de uma hora era suficiente para a eluição da lacase.

A pré-seleção, apesar de ser apenas um teste qualitativo, constitui uma etapa importante no processo de seleção de microrganismos, uma vez que as metodologias utilizadas neste procedimento são baratas e rápidas, e facilitam a detecção da produção das enzimas de interesse pelas cepas avaliadas (MARTÍNEZ et al., 1999). Através dos resultados obtidos nesta etapa, apresentados na Figura 1, os fungos $\mathrm{M}_{1}, \mathrm{D}_{2}, \mathrm{C}_{1}, \mathrm{M}_{3}, \mathrm{D}_{3}, \mathrm{C}_{2}$ e $\mathrm{C}_{3}$ foram os isolados que apresentaram maior atividade de lacase quando crescidos em meio sólido de BDA. Todos os isolados de Colletotrichum estudados produziram lacase detectada com o substrato ABTS, apenas os cultivos dos isolados $\mathrm{P}_{2}$ e $\mathrm{P}_{3}$, isolados de puerária, não apresentaram atividade de lacase sobre o substrato DMP.

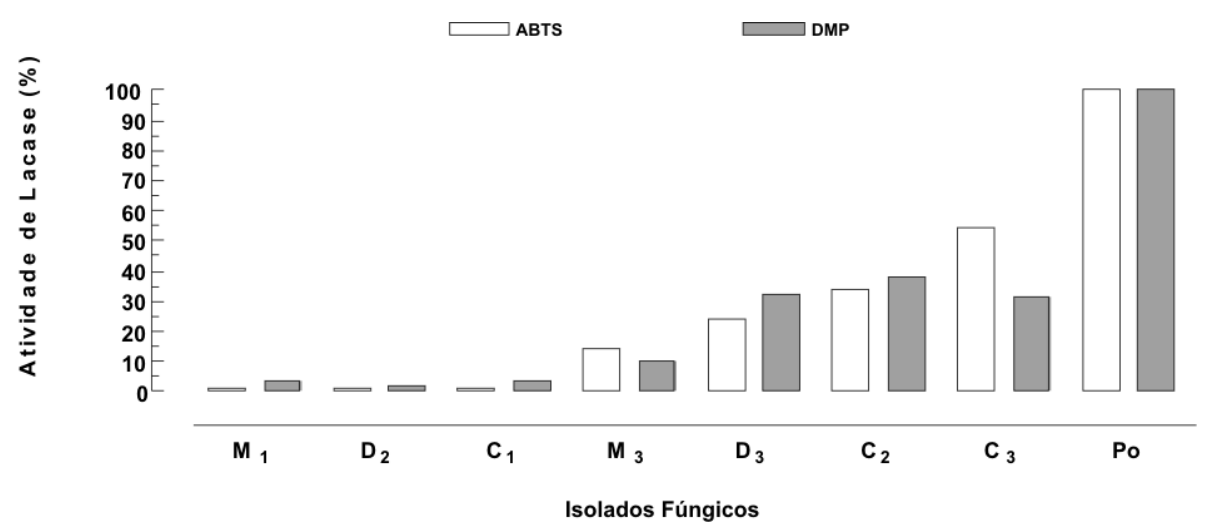

Figura 1. Comparação da produção de lacases pelos isolados de Colletotrichum e o basidiomiceto de referência Pleurotus ostreatus (Po) crescidos em meio sólido de batata-dextrose- agar.

A partir destes resultados, os isolados $\mathrm{D}_{3}$ (planta daninha), $\mathrm{M}_{3}$ (espinheira santa), $\mathrm{C}_{2}$ e $\mathrm{C}_{3}$ (cumarú) foram selecionados para a realização de testes em cultivos líquidos estáticos e agitados. Os resultados referentes ao crescimento micelial em meio líquido estão na Tabela 2, a qual mostra a variação do crescimento dos isolados $\mathrm{M}_{3}, \mathrm{D}_{3}, \mathrm{C}_{2}$ e $\mathrm{C}_{3}$ nos cultivos agitados quando comparados com os cultivos estáticos. A agitação dos meios de cultivo afetou negativamente a produção de biomassa pelos isolados de Colletotrichum. A produção de biomassa fúngica pelo $P$. ostreatus não foi influenciada pela agitação dos cultivos, sendo igual a aproximadamente 1,22 $\mathrm{g} / 1$, tanto nos cultivos estáticos como nos agitados. Para outros fungos, como por exemplo, o Aspergillus niger, tem sido descrito que a agitação constante dos meios de cultivos líquidos proporciona um aumento significativo na produção de biomassa pelos microrganismos (PAPAGIANNI; NOKES; FILER, 2001). 
Tabela 2. Avaliação da produção de biomassa fúngica pelas espécies de Colletotrichum selecionadas e do Pleurotus ostreatus (Po) em meio líquido.

\begin{tabular}{lll}
\hline \multirow{2}{*}{ Isolados } & Biomassa $(\mathbf{g} / \mathbf{l})$ & \\
\cline { 2 - 3 } & Estático & Sob Agitação \\
\hline $\mathrm{M}_{3}$ & 1,61 & 0,86 \\
$\mathrm{D}_{3}$ & 2,01 & 1,76 \\
$\mathrm{C}_{2}$ & 1,02 & 0,91 \\
$\mathrm{C}_{3}$ & 1,25 & 0,93 \\
Po & 1,22 & 1,26 \\
\hline
\end{tabular}

*pH inicial igual a 5,90

Quanto à produção de lacases, pode ser observado pelos resultados apresentados na Figura 2 que os isolados de Colletotrichum produziram lacases somente nos cultivos líquidos estáticos, sendo que o isolado que se destacou como melhor produtor foi o $\mathrm{D}_{3}$, isolado de plantas daninhas (ABTS; 35U/1 e DMP; 8U/1). As atividades enzimáticas foram plotadas considerando a atividade obtida pelo microrganismo de referência $P$. ostreatus como 100\%. A agitação tem sido descrita como um fator fundamental para a produção de lacases fúngicas (DEKKER; BARBOSA, 2001), porém a maior produção de metabólitos secundários como enzimas e toxinas por microrganismos endofíticos em cultivos estáticos têm sido relacionadas com a presença destes microrganismos no interior dos tecidos vegetais (ANDERSON; NICHOLSON, 1996; BARBOSA et al., 2002).

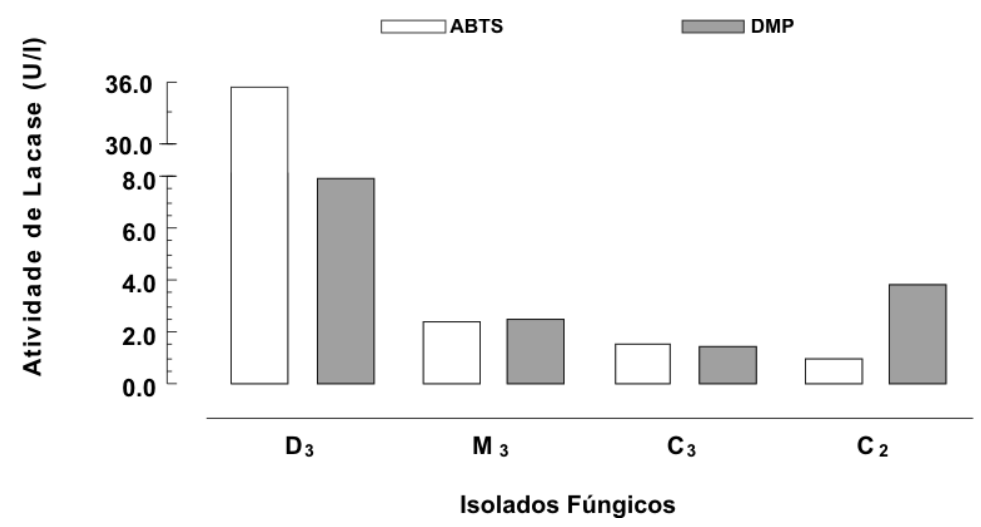

Figura 2. Avaliação da produção de lacases pelos isolados de Colletotrichum cultivados em meio líquido estático.

Para o fungo P. ostreatus, os cultivos estáticos apresentaram maiores atividades de lacase (ABTS; 480U/1 e DMP; 117U/1) do que os cultivos agitados (ABTS; 271U/1 e DMP; 57U/1), sendo que a agitação não inibiu a produção desta enzima como foi observado para os isolados de Colletotrichum. A produção de lacases por estes isolados fúngicos foi consideravelmente menor quando comparada com o $P$. ostreatus, o que pode ser explicado pelo fato das condições de cultivo utilizadas estarem otimizadas para o fungo de referência. A produção de lacase pode ser aumentada significativamente dependendo dos nutrientes presentes que influenciam sua produção (DEKKER et al., 2007). De acordo com os resultados obtidos, pode-se verificar que a metodologia empregada neste trabalho, para se detectar a atividade de lacase foi eficiente para as linhagens de Colletotrichum avaliadas e pode ser utilizada no monitoramento da presença destas polifenol oxidase em outras espécies fúngicas. 
A produção de lacases pelo Colletotrichum pode estar relacionada com os processos de fitopatogenicidade. O fungo endofítico Fusarium proliferatum, por exemplo, é um fungo produtor constitutivo de lacases e patógeno de plantações de cereais, como o trigo (KWON; ANDERSON, 2001). Estas enzimas também parecem atuar nos processos de patogênese dos grãos de arroz pela levedura Cryptococcus neoformans (WILLIAMSON, 1997), sendo responsável pela formação da melanina, um pigmento escuro que atua protegendo o microrganismo de possíveis mecanismos de defesa (ZHU; WILLIAMSON, 2004).

Portanto, a detecção da atividade das lacases em linhagens fúngicas encontradas em plantas de interesse comercialémuitoimportantepara ocontrole de pragas e pode auxiliar no desenvolvimento de novas tecnologias ecologicamente corretas para este fim. Estudos futuros envolvendo a produção destas polifenol oxidases pelos isolados de Colletotrichum serão de grande importância para o entendimento das interações destes fungos com as plantas hospedeiras, como o guaranazeiro e o algodoeiro.

\section{Agradecimentos}

Os autores agradecem ao $\mathrm{CNPq}$ e ao Curso de Especialização em Bioquímica Aplicada do Departamento de Bioquímica e Biotecnologia da Universidade Estadual de Londrina. Dr. RFH Dekker agradece ao $\mathrm{CNPq}$ pela bolsa de professor visitante.

\section{Referências}

ANDERSON, W. D.; NICHOLSON, R. L. Characterization of a laccase in the conidial mucilage of Colletotrichum Graminicola. Mycologia, New York, v. 88, n. 6, p. 996-1002, 1996.

ARDI, R.; KOBILER, I.; JACOBY, B.; KEEN, N. T.; PRUSKY, D. Involvement of epicatechin biosynthesis in the activation of the mechanism of resistance of avocado fruits to Colletotrichum gloeosporioides. Physiological and Molecular Plant Pathology, London, v. 53, n. 5-6, p. 269-285, 1998.
AZEVEDO, J. L.; MACCHERONI, W.; PEREIRA, J. O.; ARAÚJO, W. L. Endophytic microorganisms: a review on insect control and recent advances on tropical plants. Electronic Journal of Biotechnology, v. 3, n. 1, 2000. Disponível em: <http://www.ejb.org/content/vol3/ issue $1 /$ full/4>. Acesso em: 13/10/2007.

BARBOSA, A. M.; DEKKER, R. F. H.; HARDY, G. E. Veratryl alcohol as inducer of laccase by the ascomycete Botryosphaeria sp., when screened on polymeric dye poly R-478. Letters in Applied Microbiology, Oxford, v. 23, n. 2, p. 93-96, 1996.

BARBOSA, A. M.; SOUZA, C. G. M.; DEKKER, R. F. H.; FONSECA, R. C.; FERREIRA, D. T. Phytotoxin produced by Bipolaris euphorbiae in vitro is effective against the weed Euphorbia heterophylla. Brazilian Archives of Biology and Technology, Curitiba, v. 45, n. 2, p. 233-240, 2002.

BENTES, J. L. S.; BARRETO, R. W. Reavaliação taxonômica de Colletotrichum guaranicola Albuq. agente causal da antracnose do guaranazeiro. Acta Amazônica, Manaus, v. 34, n. 1, p. 129-131, 2004.

CHUNG, K. R.; SHILTS, T.; LI, W.; TIMMER, L. W. Engineering a genetic transformation system for Colletotrichum acutatum, the causal fungus of lime anthracnose and postbloom fruit drop of citrus. FEMS Microbiology Letters, Amsterdam, v. 213, n. 1, p. 33-39, 2002.

COLL, P.; TABERNERO, C.; SANTAMARIA, R.; PEREZ, P. Characterization and structural analysis of the laccase I gene from the newly isolated ligninolytic basidiomycete PM 1 (CECT2971). Applied and Environmental Microbiology, Washington, v. 59, n. 12, p. 4129-4135, 1993.

COUTO, S. R.; HERRERA, J. L. T. Industrial and biotechnological applications of laccases: A review. Biotechnology Advances, New York, v. 24, n. 5, p. 500513, 2006.

DEKKER, R. F. H.; BARBOSA, A. M. The effects of aeration and veratryl alcohol on the production of two laccases by the ascomycete Botryosphaeria sp. Enzyme and Microbial Technology, New York, v. 28, n. 1, p. 8188, 2001.

DEKKER, R. F. H.; BARBOSA, A. M.; GIESE, E. C.; GODOY, S. D. S.; COVIZZI, L. G. "Influence of nutrients on enhancing laccase production by Botryosphaeria rhodina MAMB-05". International Microbiology, Barcelona, v. 10, n. 3, p. 177-186, 2007.

ELEGIR, G.; DAINA, S.; ZOIA, L.; BESTETTI, G.; ORLANDI, M. Laccase mediator system: Oxidation of recalcitrant lignin model structures present in residual 
Kraft lignin. Enzyme and Microbial Technology, New York, v. 37, n. 3, p. 340-346, 2005.

GOODWIN, P. H.; OLIVER, R. P.; HSIANG, T. Comparative analysis of expressed sequence tags from Malva pusilla, Sorghum bicolor, and Medicago truncatula infected with Colletotrichum species. Plant Science, Limerick, v. 167, n. 3, p. 481-489, 2004.

HARTREE, E. S. Determination of protein: a modification of Lowry method that gives a linear photometric response. Analytical Biochemistry, New York, v. 48, n. 2, p. 422427, 1972.

HERBERT, C.; O'CONNELL, R.; GAULIN, E.; SALESSES, V.; ESQUERRÉ-TUGAYÉ, M. T.; DUMASA, B. Production of a cell wallassociated endopolygalacturonase by Colletotrichum lindemuthianum and pectin degradation during bean infection. Fungal Genetics and Biology, Orlando, v. 41, n. 2, p. 140-147, 2004.

IKEHATA, K.; BUCHANAN, I. D.; SMITH, D. W. Recent developments in the production of extracellular fungal peroxidases and laccases for waste treatment. Journal of Environmental Engineering and Science, Ottawa, v. 3, n. 1, p. 1-19, 2004.

JAOUANI, A.; GUILLEN, F.; PENNINCKX, M. J.; MARTÍNEZ, A. T.; MARTÍNEZ, M. J. Role of Pycnoporus coccineus laccase in the degradation of aromatic compounds in olive oil mill wastewater. Enzyme and Microbial Technology, New York, v. 36, n. 4, p. 478486, 2005.

KIM, K. D.; OH, B. J.; YANG, J. Differential interactions of a Colletotrichum gloeosporioides isolate with green and red pepper fruits. Phytoparasitica, Bet Dagan, v. 27, n. 2, p. 97-106, 1999.

KING'ORI, P. N.; MASABA, D. N. Distribution and persistence of benomyl resistance in populations of Colletotrichum coffeanum in coffee. Kenya Coffee, Nairobi, v. 56, n. 654, p. 1071-1074, 1991.

KUMAR, A. SATYAVIR. Evaluation of biological control agents against red rot (Colletotrichum falcatum) of sugarcane. Annals of Applied Biology, Warwick, v. 132, p. 72-73, 1998.

KWON, S. I.; ANDERSON, A. J. Laccase isozymes: production by an opportunistic pathogen, a Fusarium proliferatum isolate from wheat. Physiological and Molecular Plant Pathology, London, v. 59, p. 235-242, 2001.

LEITE, O. D.; ENDO, A. S.; FELISBINO, M. P.; OBARA-DOI, S. M.; FONSECA, R. C.; BARBOSA, A. M. Thermal and $\mathrm{pH}$ stabilities of laccases from
Pleurotus ostreatus produced in the presence of veratryl alcohol. In: LATIN AMERICAN BIODEGRADATION AND BIODETERIORATION SYMPOSIUM, 3., 1998, Florianópolis. Anais... Florianópolis: UFSC, 1998. p. 34.

LEITE, O. D.; FATIBELLO-FILHO, O.; BARBOSA, A. M. Determination of catecholamines in pharmaceutical formulations using a biosensor modified with a crude extract of fungal laccase (Pleurotus ostreatus). Journal of the Brazilian Chemical Society, São Paulo, v. 14, n. 2, p. 297-303, 2003.

LEONOWICZ, A.; CHO, N.; LUTEREK, J.; WILKOLAZKA, A.; WOJTAS-WASILEWSKA, M.; HOFRICHTER, M.; WESENBERG, D.; ROGALSKI, J. Fungal laccase: properties and activity on lignin. Journal of Basic Microbiology, Berlin, v. 41, n. 3/4, p. 185-227, 2001.

LEVIN, L.; RAMOS, A. M.; PARISI, M.; GALLY, M. Screening of Colletotrichum (Ascomycota) isolates, causal agents of soybean Anthracnose, for laccase production. Boletin de la Sociedad Argentina de Botanica, La Plata, v. 42, n. 1-2, p. 71-77, 2007.

MARTÍNEZ, M. J.; BARRASA, J. M.; GUTIÉRREZ, A.; DEL RÍO, J. C.; MARTÍNEZ, A. T. Fungal screening for biological removal of extractives from Eucalyptus globulus wood. Canadian Journal of Botany, Ottawa, v. 77, n. 10, p. 1513-1522, 1999.

MAYER, A. M.; STAPLES, R. C. Laccase: new functions for an old enzyme. Phytochemistry, New York, v. 60, n. 6, p. 551-565, 2002.

MENDONÇA, H. A.; SANTOS, J. B.; RAMALHO, M. A. P.; FERREIRA, D. F. Genetic control of the fungus Colletotrichum lindemuthianum (Sacc. \& Magn.) Scrib. reaction and corona color in common bean (Phaseolus vulgaris L.). Genetics and Molecular Biology, Ribeirão Preto, v. 21, n. 3, p. 335-341, 1998.

NELSON, N. A. Colorimetric adaptation of the Somogyi method for determination of glucose. The Journal of Biological Chemistry, Bethesda, v. 153, n. 1, p. 376-380, 1944.

OKANE, I.; NAKAGIRI, A. ITO, T. Endophytic fungi in leaves of ericaceous plants. Canadian Journal of Botany, Ottawa, v. 76, n. 4, p. 657-663, 1998.

PAPAGIANNI, M.; NOKES, S. E.; FILER, K. Submerged and solid-state phytase fermentation by Aspergillus niger: Effects of agitation and medium viscosity on phytase production, fungal morphology and inoculum performance. Food Technology and Biotechnology, Zagreb, v. 39, n. 4, p. 319-326, 2001. 
PETRINI, O.; PEREIRA, J. O.; AZEVEDO, J. L. Endophytic fungi of Stylosanthes: A first report. Mycologia, New York, v. 85, n. 3, p. 362-364, 1993.

REZENDE, M. I.; BARBOSA, A. M.; VASCONCELOS, A. F. D.; HADDAD, R.; DEKKER, R. F. H. Growth and production of laccases by the ligninolytic fungi, Pleurotus ostreatus and Botryosphaeria rhodina, cultured on basal medium containing the herbicide, Scepter ${ }^{\circledR}$ (imazaquin). Journal of Basic Microbiology, Berlin, v. 45, n. 6, p. 232240, 2005.

ROCHA, J. D.; OLIVEIRA, N. T.; MENEZES, M. Comparison of inoculation methods efficiency for evaluation of Colletotrichum gloeosporioides isolates pathogenicity on passion fruits (Passiflora edulis). Brazilian Archives in Biology and Biotechnology, Curitiba, v. 41, n. 1, p. 145-153, 1998.

ROY, J. J.; ABRAHAM, T. E.; ABHIJITH, K. S.; SUJITH KUMAR, P. V.; THAKUR, M. S. Biosensor for the determination of phenols based on Cross-Linked Enzyme Crystals (CLEC) of laccase. Biosensors and Bioelectronics, Oxford, v. 21, n. 1, p. 206-211, 2005.

SILVA-MANN, R.; KALINKA C. C. SALGADO, K. C. C.; VIEIRA, M. G. G. C.; MACHADO, J. C. Variabilidade genética de isolados do complexo Colletotrichum associados a sementes de algodoeiro, por meio de técnicas moleculares e inoculação em plantas. Fitopatologia Brasileira, Brasilia, v. 27, n. 1, p. 27-32, 2002.
SOMOGYI, M. A. A new reagent for determination of sugars. The Journal of Biological Chemistry, Bethesda, v. 160, n. 1, p. 61-68, 1945.

SOUZA, R. F.; GOMES, R. C.; COELHO, R. R. R.; ALVIANO, C. S.; SOARES, R. M. A. Purification and characterization of an endochitinase produced by Colletotrichum gloeosporioides. FEMS Biotechnology Letters, Holanda, v. 222, n. 1, p. 45-50, 2003.

SUGUIMOTO, H. H.; BARBOSA, A. M.; DEKKER, R. F. H.; CASTRO-GOMEZ, R. J. H. Veratryl alcohol stimulates fruiting body formation in the oyster mushroom, Pleurotus ostreatus. FEMS Microbiology Letters, Amsterdam, v. 194, n. 2, p. 235-238, 2001.

VOGEL, H. J. A convenient growth medium for Neurospora crassa. Microbial Genetics Bulletin, Columbus, v. 13, n. 1, p. 42-43, 1956.

WILLIAMSON, P. R. Laccase and melanin in the pathogenesis of Cryptococcus neoformans. Frontiers in Bioscience, Tampa, v. 2, p. 99-107, 1997.

ZHU, X.; WILLIAMSON, P. R. Role of laccase in the biology and virulence of Cryptococcus neoformans. FEMS Yeast Research, Amsterdam, v. 5, n. 1, p. 1-10, 2004. 
